Research paper

\title{
Research performance as a quality signal in international labor markets: Visibility of business schools worldwide through a global research performance system
}

\author{
Olga Ryazanova ${ }^{\mathrm{a}, *}$, Peter McNamara ${ }^{\mathrm{a}}$, Herman Aguinis ${ }^{\mathrm{b}}$ \\ ${ }^{a}$ Maynooth University School of Business, North Campus, Maynooth University, Maynooth, Co. Kildare, Ireland \\ b School of Business, George Washington University, 2201 G Street, NW Washington, DC 20052, United States
}

\section{A R T I C L E I N F O}

\section{Keywords:}

International business research performance

International hiring

Business schools

Research performance

Signaling theory

Global mobility

\begin{abstract}
A B S T R A C T
Attracting talent with international capabilities is critical for the internationalization of business schools and other knowledge-intensive service-industry organizations. However, limited coverage beyond the top cohort of business schools in existing research-based rankings does not allow the majority of institutions to use these rankings as global signaling systems of their research performance. This is particularly detrimental to the development of younger research fields, such as International Business (IB). Our Global Research Performance (GRP) system affords visibility to 1029 institutions that publish in seven prominent IB journals and to a broader cohort of 3352 institutions that publish in 149 high-impact business and management journals. GRP empowers IB and other scholars to demonstrate their contribution to their organizations' legitimacy and promotes a datadriven approach to international talent recruitment.
\end{abstract}

\section{Introduction}

The globalization of the world economy has put pressure on business schools to deliver an education experience that prepares students for global markets and mobility (Caligiuri \& Bonache, 2016; Hertig, 2016). Achieving this goal is facilitated by the internationalization of knowledge workers (i.e., faculty) who serve as "service providers," and are the key source of competitive advantage in knowledge-intensive service industries (Brock, 2012; Thomas, Lorange, \& Sheth, 2013). International faculty, returning academic expatriates, and academics who actively engage with the international business (IB) research community are particularly suited to creating and disseminating such international knowledge (Pherali, 2012).

Harvey \& Moeller (2016) identified global labor mobility as one of six key themes in future IB research. Awareness regarding potential employers is a key prerequisite of global labor mobility and a key challenge for both employers and workers. Most global service-industry firms tend to hire locally for geographically dispersed branches of an organization, while business schools often attract faculty and $\mathrm{PhD}$ students directly from the international labor market. Direct crossborder hiring involves high degree of information asymmetry, with employers and employees alike struggling to make sense of unfamiliar information cues.
Signaling theory (Connelly, Certo, Ireland, \& Reutzel, 2011; Spence, 1973) is a useful conceptual lens for understanding the matching process between mobile labor and employers in such an environment. How can business schools compete in a globalized market and how can they signal their reputation to potential employees? Research productivity is one of the most institutionalized sources of visibility and legitimacy in higher education (Baden-Fuller \& Ang, 2001). Thus, it is not surprising that the research performance of business schools, as indicated by global and national rankings, largely determines their reputation (Wedlin, 2011). This presents a challenge for the majority of business schools worldwide, because traditionally only a small cohort of top-tier institutions enjoys global visibility (Hommel \& Thomas, 2014).

We argue that the existing research-based rankings serve a narrow audience of signal senders and receivers; namely, already globally prominent institutions. By using a narrow list of journals to gather research performance data and focusing on a limited number of already prominent "world-class" institutions, these rankings fail to create international visibility for the vast majority of business schools, essentially signaling that they "do not count."

Our article offers a global research performance (GRP) system to serve the need of business schools to signal and build legitimacy in international markets. GRP presents the most global and comprehensive research information system to date, covering 3352 higher education

\footnotetext{
* corresponding author.

E-mail addresses: olga.ryazanova@mu.ie (O. Ryazanova), peter.mcnamara@mu.ie (P. McNamara), haguinis@gwu.edu (H. Aguinis).
} 
Table 1

Empirical applications of the Global Research Performance (GRP) system.

\begin{tabular}{|c|c|}
\hline Stakeholder group & Application of the GRP system \\
\hline IB researchers & $\begin{array}{l}\text { - Demonstrate the contribution of their research to their institutions' legitimacy } \\
\text { - Facilitate international networking by revealing a broad range of institutions producing IB research } \\
\text { - Highlight the "emerging" IB institutions that might need support from the IB community }\end{array}$ \\
\hline Faculty and $\mathrm{PhD}$ students & $\begin{array}{l}\text { In the international job search: } \\
\text { - Calibrate expectations in relation to research environment in a potential workplace } \\
\text { - Signal the quality of their academic pedigree to prospective employers, particularly for early-career } \\
\text { researchers }\end{array}$ \\
\hline $\begin{array}{l}\text { Academic managers (e.g., deans, department chairs, and other decision } \\
\text { makers) }\end{array}$ & $\begin{array}{l}\text { - Support hiring and retention of international talent } \\
\text { - Provide a foundation for resource claims at the department and university levels } \\
\text { - Demonstrate research excellence in relationships with external stakeholders, such as alumni and } \\
\text { corporate partners }\end{array}$ \\
\hline Science foundations and other funding agencies & $\begin{array}{l}\text { - Assess the impact of funding regimes and science policy at the organizational, national, and regional } \\
\text { levels }\end{array}$ \\
\hline
\end{tabular}

${ }^{\text {a }}$ For users of the GRP system who are interested in assessing the individual-level productivity of a given school, it is advisable to control for the size of the school, for example by normalizing the absolute output by the number of research-active faculty.

institutions in 127 countries that have published at least one article in 149 business journals during the 2007-2015 time period. Moreover, our $\mathrm{IB}^{1}$ dataset, which is a sub-set of the GRP system, includes 1029 institutions from 75 countries that published in seven highly-recognized IB journals. We provide the entire GRP system to readers. ${ }^{2}$

We focus on the field of IB specifically because, for the IB scholarly community, the visibility challenge is particularly acute. The field of IB is often considered a sub-field within the field of general management (Adler \& Harzing, 2009) and most IB journals are relatively young compared to many management journals (Tüselmann, Sinkovics, \& Pishchulov, 2016). This has resulted in their slow inclusion in global research rankings. Low visibility of IB journals has a knock-on effect on visibility of institutions supporting IB research and their ability to attract IB scholars in international labor markets.

Recently, there has been an increase in the number of visible IB journals in prominent journal rankings (e.g., Tüselmann et al., 2016). However, the research rankings of IB institutions have not as of yet mirrored this positive trend, maintaining the practice of focusing exclusively on a few top institutions only. As argued by Tüselmann et al. (2016), IB researchers' best work cannot be captured by observing a narrow range of journals. Equally, the diversity of contributions to IB research cannot be captured by focusing on a narrow range of institutions, which are often geographically bounded.

Our study makes three interconnected contributions to the IB research community and IB literature. First, for the community of IB scholars, the IB journal subset of the global research performance (GRP) system offers an opportunity to highlight the role of publications in IB journals in overall research performance of these scholars' workplaces and an opportunity to identify the wider range of institutions publishing research in IB journals. Both of these opportunities are central to the development of IB research groups worldwide and collaboration among institutions around IB research topics.

Second, we contribute to the theme of global mobility of self-initiated expatriates (SIEs), defined as employees who take the initiative to seek employment in a foreign location (Doherty, 2013), by bringing the hiring of SIEs to the forefront of internationalization processes in business schools. We highlight the importance of signaling business

\footnotetext{
${ }^{1}$ We use the label "IB" for research in international business, international management, and international strategy. While some have argued that these fields are distinct and have defined boundaries (Eden, Dai, \& Li, 2010), in practice these boundaries are permeable and journals tend to publish research from multiple sub-disciplines. In addition, IB research is also published regularly in general management journals.

${ }^{2}$ Available via Journal of World Business website, the website of the Maynooth University School of Business, www.hermanaguinis.com, or by contacting the authors for an Excel spreadsheet upon request.
}

schools' research-based reputation in attracting high-quality talent in international labor markets. We further discuss the structural features of signaling systems that enable such systems to accommodate global diversity, with specific focus on the academic labor market.

Third, we deliver a conceptual link between the scientometric literature that focuses on research performance-based rankings (e.g., Treviño, Mixon, Funk, \& Inkpen, 2010; Xu, Poon, \& Chan, 2014) and the literature on internationalization of business schools (e.g., Guillotin \& Mangematin, 2015). We discuss the impact that particular methodological approaches can have on the ability of non-globally prominent business schools to internationalize by attracting SIEs. This critical analysis is a necessary step towards integration of what has so far been siloed research around internationalization-related processes in business schools (e.g., Enders, 2014; Erkkilä, 2013; Wedlin, 2011). As an empirical contribution to internationalization practices of business schools, we offer a theory-driven solution to non globally prominent institutions in the shape of the GRP system which significantly improves the efficiency of signaling and increases visibility of potential employers and employees alike.

The aforementioned contributions have implications for multiple stakeholders, including academic managers (e.g., deans, department chairs, and other decision makers), faculty, and $\mathrm{PhD}$ students. As a preview and summary, Table 1 describes potential applications of the GRP system for various stakeholders, particularly in IB.

\section{Conceptual background}

\subsection{Conceptual approach to signaling in international markets}

What makes a signaling system efficient? How does internationalization change established signaling systems? Drawing insights from signaling theory (Connelly et al., 2011; Spence, 1973), we argue that an efficient signaling system relies on four fundamental principles. The first is signal fit. A signal should closely reflect the underlying unobservable quality for which it serves as a proxy. This is important for the signaling to be useful for the receiver.

Second, a signal should be observable by the target audience of receivers. This second principle of signal observability, usually taken as a given within a single-country setting, may become a challenge in global signaling. Knowledge-intensive service-industry firms often use membership of local professional bodies as a signal of legitimacy.

Third, consider the principle of signal cost. In an efficient signaling system, signal cost differentiates between high-quality institutions and lower-quality institutions because, for the institutions of lower quality, it is too costly to imitate the signals of high quality. The fundamental assumption behind this principle is that all organizations in the market 


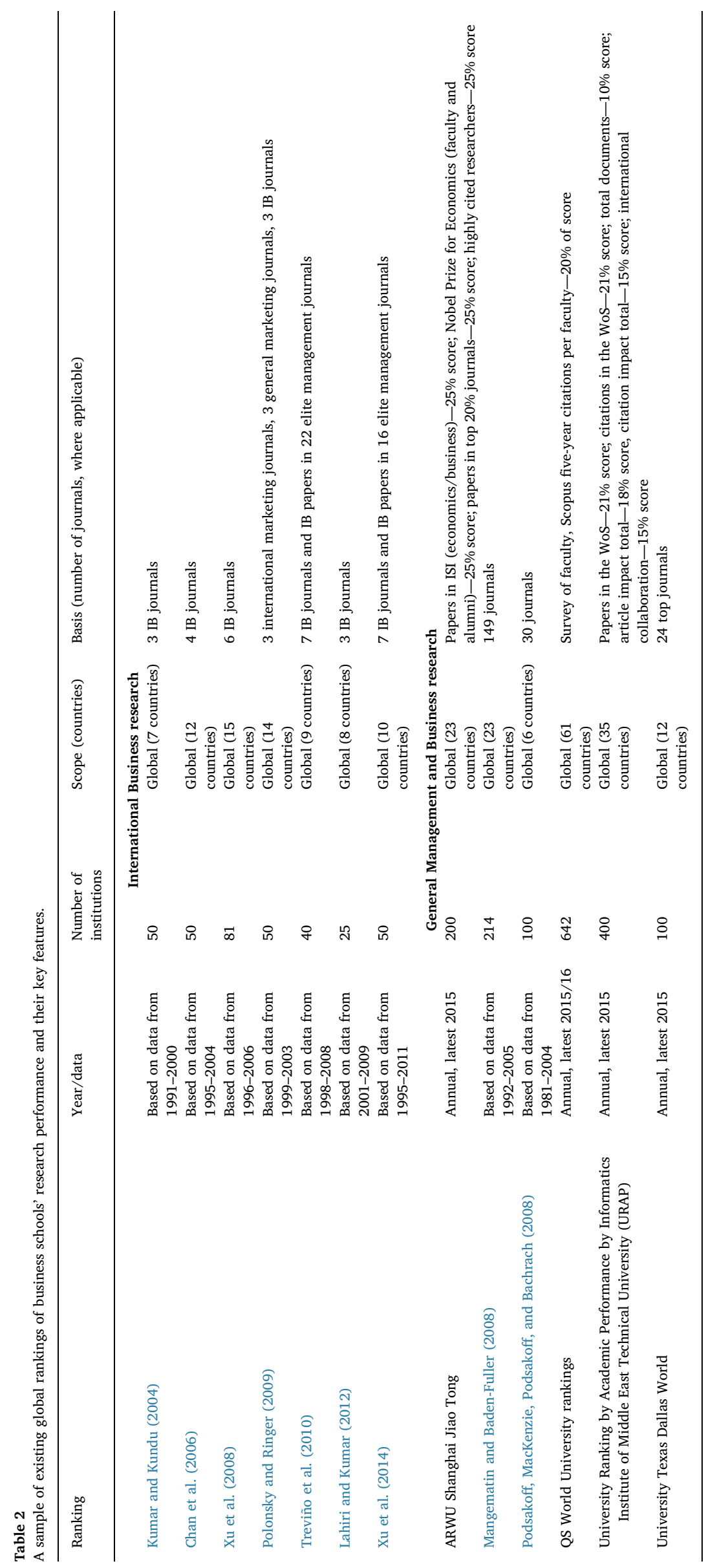


have the same access to this signaling system (i.e., nobody is discriminated against or has additional signaling costs that are unrelated to the underlying quality that a signal represents). In the context of international markets, organizations face multiple barriers unrelated to their core quality.

Fourth, the principle of signal scope means that the signal should enable differentiation between high- and low-quality signalers across the entire market. In a global signaling system, this market is no longer limited to one national setting. While the ideal of including all organizations is hard to achieve (although not impossible in the Internet age), the higher the number of organizations visible in the system, the more useful it is for international audiences.

\subsection{Global rankings of research: business school legitimacy in international labor markets}

We now apply each of the four signaling principles to our specific research setting. Regarding signal fit, in the business school context, two aspects may decrease fit: the level of analysis and the definition of what is "research that counts." Signaling systems that measure research at the entire university level only, such as the Times Higher Education ranking, deliver poor signal fit for the business school audience because research performance in these rankings can be driven by other disciplines within a university. To ensure a good fit, a signal should capture all high-quality research produced in business schools. At the national level, research assessment systems invest significant resources into fine-grained evaluation of research outputs, which improves signal fit. In these systems some research may remain unaccounted for, because institutions make strategic decisions to exclude some faculty from the assessment (Pidd \& Broadbent, 2015; Stern, 2016). At the global level, many existing rankings rely on a relatively narrow list of "top" journals (e.g., Baden-Fuller \& Ang, 2001; Linton, 2012), effectively claiming that anything published outside this list is not considered to be good research.

Second, consider the principle of signal observability. Numerous differences exist between national systems of research evaluation (Saunders, Wong, \& Saunders, 2011), of which potential signal receivers from outside the country may not be aware. The UK, Australia, and New Zealand national assessments of research are predominantly structured around expert panels, while Germany and Denmark place great emphasis on scientometric assessment (Wilsdon et al., 2015). Some countries publish their research assessments primarily in their local language (e.g., Italy's VQR process) and linguistic barriers may prevent outsiders from engaging with the results. Accordingly, to ensure better observability of research performance signals in the GRP system, we seek to make our data available through the Journal of World Business, a journal with a strong orientation towards international audiences.

The third principle of efficient global signaling is the unambiguous link between signal cost and the underlying quality that an organization is signaling. In the case of business schools, the quality in question is that of their research environment. Business schools signal this quality globally through research outputs which are predominantly published in English-language journals. This makes an institution's endowment of linguistic capital (i.e., the ability of faculty to write competently in academic English) a source of heterogeneity within the industry. IB research has already identified language as a factor influencing status, trust, collaboration, and career success in multinational organizations (e.g., Itani, Järlström, \& Piekkari, 2015; Neeley, 2013; Tenzer \& Pudelko, 2017). In our setting, language may restrict access to global signaling. This does not mean that institutions in non-English speaking countries cannot achieve high performance. These institutions may have to implement a different set of policies than their peers located in English-speaking world, which might result in additional investments on their part.

Finally, examining the scope of existing signaling systems, national systems of research evaluation tend to include most organizations in the country and provide in-depth exploration of their quality. The cost of such full-scale national assessment of research quality is high. Stern (2016) estimated that REF 2014 cost UK taxpayers $£ 246 \mathrm{~m}$. This level of investment may not be feasible for less wealthy countries. More importantly, results of these evaluations are hard to compare across countries. The top institutions of a national research system do not necessarily qualify as high-quality institutions on a global scale (Horta, 2009; Saunders et al., 2011). The trend towards grouping assessment results into categories, such as $4 * / 3 * / 2 * / 1 *$ categories in REF, makes it even more difficult to find international benchmarks for an institution.

\subsubsection{Critical analysis of existing signaling and global rankings}

Despite a plethora of rankings at the national and global levels, there are none that could serve as an efficient global signaling system, according to the principles discussed earlier. Table 2 includes a sample of global research-based rankings that focus on the discipline of business, management in general and IB in particular. The ARWU Shanghai ranking, the University Ranking by Academic Performance (URAP) ranking, the QS World University ranking, and the ranking by Mangematin and Baden-Fuller (2008) are all based on a broad definition of research and cover more than 20 countries. They, therefore, satisfy most of the signaling criteria discussed above, although their coverage of institutions is quite limited.

There are methodological challenges with these rankings. First, some use arbitrary weighting of different score components to construct a multidimensional measure of research performance, which introduces subjective judgement (Pidd \& Broadbent, 2015). For example, the URAP weights the article impact component of its scores at $18 \%$ without any theoretical or other justification. Second, the use of ordinal scales, for example, by Mangematin and Baden-Fuller (2008) does not show how large a research output a school must add to its current performance level to move up the ranks. The use of normalized scores instead of raw numbers may give the false impression that the distance between the ranks is the same at any level of research performance. Third, the QS ranking combines data from faculty surveys with citation data from Scopus. As a result, it is only partly a ranking of research performance, with $80 \%$ of the score coming from other dimensions, such as research prestige and student-to-faculty ratio.

In the field of IB, existing rankings focus on a small cohort of topperforming schools, and give IB audiences no information beyond the 81 institutions in 15 countries covered in the ranking by $\mathrm{Xu}$, Yalcinkaya, and Seggie (2008). The growth and development of the field depends on the ongoing contribution of IB scholars to the body of IB knowledge. If the contribution of non globally prominent institutions is not acknowledged and rewarded with legitimacy, these organizations may lack motivation to support IB research.

In this article, we offer a research information system that allows for decisions informed by data that have not been transformed by a "blackbox evaluation machine" (Hicks, Wouters, Waltman, de Rijcke, \& Rafols, 2015: 430). We follow the lead of some national research evaluation systems, such as the German CHE (Usher \& Medow, 2009), which provide indicators without compiling them into ordered league tables. By making raw data available, our system gives users the flexibility of adding any factors they wish (for instance, size or governance structure) prior to making a judgement on the quality signal. Our system offers a significant advancement in transparency, scope, and replicability, which were outlined as best practices in the Leiden Manifesto for research metrics (Hicks et al., 2015) and for IB in particular (e.g., Aguinis, Cascio, \& Ramani, 2017; Cuervo-Cazurra, Andersson, Brannen, Nielsen, \& Reuber, 2016).

\section{Method}

Our GRP system is based on the principles of efficient global signaling discussed in Section 2 (Conceptual background). Following these 
principles, we produce both an IB dataset and the wider business and management dataset of institutional research performance.

\subsection{Signal fit: focus on the field of business and management}

To source journals for our GRP system, we chose three subject categories, namely "Business," "Business, Finance," and "Management," from Clarivate Analytics' Journal Citation Reports (JCR). ${ }^{3}$ These classifications are appropriate for IB journals and have been used by prior studies (e.g., Mangematin \& Baden-Fuller, 2008). Clarivate Analytics works proactively to weed out poor quality journals, such as predatory journals (Harzing \& Adler, 2016), from their JCR lists, which they do through journals suspensions and other quality control practices. This gave us confidence that in seeking to expand of view of the business and management field we will use reliable sources as a basis of our research performance metrics.

\subsection{Signal observability: choice of journals and metrics}

Selection of outputs for inclusion in any research assessment is a highly contested issue (Willmott, 2011). In our methodology, we chose to focus on visible peer-reviewed journals.

\subsubsection{Journal selection}

Compiling journal lists involves two main challenges, starting with the selection of the number of journals to be included. Earlier we argued that limiting the list to a small number of journals results in a poor signal fit for a global audience. Following this logic, one might decide that including all journals visible in the Web of Science or Scopus would guarantee that all relevant research is captured. However, expanding the list of journals indefinitely might lower the standards in business and management research in general, and IB research in particular. For this reason, we limited our list by journals with highest visibility that provide $85 \%$ cumulative citation coverage in three chosen JCR categories. In terms of citation coverage, this threshold seems to be an intuitive point of saturation, below which a marginal increase in citation coverage drops by about $40 \%$. To determine whether the journal just below the threshold of $85 \%$ should be included in the list, we followed the simple logic: if the journal in question has citation coverage close to the average citation coverage of journals located between $80 \%$ and $85 \%$, it should be included, if its citation coverage is significantly lower, it should not be included. ${ }^{4}$

A second challenge is to identify the relative importance of journals. Some authors rely directly on the number of citations that each paper has attracted (e.g., Xu et al., 2014). This approach has its problems. Citations are highly time-dependent and, consequently, research published earlier has an advantage over research published more recently, even if average annual citations are taken as a measure. Citations also represent a moving target, and for large datasets their count can change significantly over the data collection period. For this reason, most research evaluations use the metrics of journal quality as a proxy for article quality or visibility.

Two main approaches to journal quality assessment are stated preference (expert opinion) and revealed preference (citations attracted by journals). Most of the existing journal lists, such as the CABS list, the UTD list, and the lists used in Harzing's Journal Quality List (Harzing, 2016; Mingers \& Harzing, 2007), are based on the stated preference approach. This approach has been shown to be prone to exposure bias, where experts assign higher ranks to the journals more familiar to them (Serenko \& Bontis, 2011). National research assessment projects are

\footnotetext{
${ }^{3}$ The database was previously owned by Thomson Reuters, which sold it to Clarivate Analytics in 2016.

${ }^{4}$ We refrain from calling the JCR journals that did not make it to our journal list "poor quality." Citation rates are just one metric of research quality, which disadvantages recently created journals, journals catering to highly specialized sub-fields of IB research, and journals oriented towards the audience of practitioners.
}

designed to differentiate between institutions within their nation's boundaries. In this context, they may highlight the journals that are of particular importance within their region, but less so globally.

Assessing journals by revealed preferences is essentially similar to a popular vote: scholars independently express interest in published research by citing it in their own work. There are some challenges to this approach, such as the inability to distinguish between core and peripheral citations (Kacmar \& Whitfield, 2000). That said, the revealed preference method, which underlies Clarivate Analytics' JCR Impact Factors (IFs) and Scopus' SCImago Journal Rank, is closer to the ideal of transparent and replicable metric promoted by the Leiden Manifesto.

In an attempt to bring together these two approaches, meta-rankings, such as those developed by Tüselmann, Sinkovics, and Pishchulov (2015) and Tüselmann et al. (2016), used both JCR data and expert opinion-based rankings, which were combined through Data Envelopment Analysis, complemented by CARD and random forests methods to deal with the missing data, as well as Nash bargaining model to define the rank discrimination threshold. This level of methodological complexity is likely beyond the capability of many users to competently assess and replicate. The GRP system is a user-friendly, theory-driven tool that has to balance simplicity in replication with acceptable construct validity. Bringing several journal rankings together, each with its own idiosyncrasies, does not necessarily result in a less idiosyncratic meta-ranking. At the same time, some choices have to be made in the process of constructing a metaranking (e.g., which journal lists to include), which makes the procedure less replicable than we seek our GRP approach to be.

Following the logic discussed above, we decided to use the JCR, one of the most established lists of visible journals in the field of business and management. We collected JCR data for every year between 2007 and 2015 for our chosen subject categories, and merged these journal lists to calculate an average 5Year Impact Factor (5YIF) for each journal. As a metric, 5YIF is less sensitive than 2YIF to short-term variations in citation counts related to special issues of journals or to particularly impactful articles (Mingers \& Yang, 2017). Our logic for choosing 5YIF over other available metrics, as well as the strategies for dealing with missing data, where journals have an incomplete set of 5YIFs in 2007-2015 are discussed in detail in Appendix 1 in Supplementary material, which can be found in the online supplement. Appendix 1 in Supplementary material provides additional insights into the logic behind some of the decisions we made in developing the methodology of the GRP system, such as the choice of the journal visibility metric, the strategies for dealing with missing JCR data, the definition of a threshold of journal inclusion, the strategy for dealing with authors who have multiple affiliations, and our treatment of the concept of research visibility and impact.

The full list, which included 367 journals, was then sorted by average 5YIF. The top 149 journals that provided $85 \%$ citation coverage were selected for the final list (provided in Appendix 1 in Supplementary material available as an online supplement). These journals equate to $41 \%$ of the total population of JCR journals in these categories in 2007-2015. Overall, 84\% of these journals are considered by CABS to be at rank 3 or above. Rank 3 journals are regarded as "very selective in what they publish" and "heavily refereed."

\subsubsection{Data collection}

For each of our journals, we collected bibliometric data from the Web of Science database. Only research papers and reviews were included in the publication output. ${ }^{5}$ We grouped the data by organization and collected these data for three-year periods: 2007-2009, 2010-2012, and 2013-2015. We weighted the number of papers published by each

\footnotetext{
${ }^{5}$ Other relevant research outputs include, for example, working papers and papers currently under review. However, the methodological approach that we promote in our article assumes that a good signal of research prominence should be easy to replicate by anyone who wants to check that the data in the system are accurate. For this reason, we only used the data from Web of Science which are available to anyone with the subscription. These data do not currently include working papers and papers under review.
} 
organization by the average 5YIF of the relevant journal in the respective period (i.e., publications in 2007-09 would be weighted by average 5YIF of a journal in 2007-09). We named this weighted measure of research performance "visibility-adjusted volume." Multiplying the number of papers by the impact factor (IF) of a respective journal accounts for the visibility of publications to the scientific community.

\subsection{Signal cost: peer-reviewed only}

Significant time and intellectual effort is associated with the peerreview process. This cost enables papers published in peer-reviewed journals to serve as a signal of quality. The GRP system only includes peer-reviewed papers and reviews.

\subsection{Signal scope: global reach}

Our approach seeks to provide visibility to all organizations contributing to knowledge creation in the field of business and management. The GRP system includes all institutions that published at least one paper between 2007 and 2015. For each of three time periods we provide the organization-level data on the count of papers published and the visibilityadjusted count of papers. Following the example of prior studies, we used the whole-count measure of papers for allocating publications to organizations (Mangematin \& Baden-Fuller, 2008). The whole-count method gives equal recognition to all institutions that appear on the paper and this method is almost always used by Clarivate Analytics (Pendlebury, 2008). Using a fractional count, for example, would allocate half of a publication to a school if a paper was co-authored by two academics from different institutions, might allow us to account for knowledge input differently. Such fine-grained data are not available in the Web of Science database. Given the size of the dataset, it was not feasible to read each paper and account for the proportion of co-authorship. Co-authors may have different inputs into the project, which makes the weighting of credit a difficult and potentially divisive task (Floyd, Schroeder, \& Finn, 1994). In a similar way, the data do not allow us to track the cases of authors with multiple affiliations, but, assuming that such cases exist in our dataset, full unit of output was assigned to each mentioned institution. ${ }^{6}$

We provide the total volume and weighted output for 2007-2015 to give an estimate of each organization's research performance for a nineyear period. This aggregated measure might be useful for longer-term planning of research performance-related strategies in business schools. Overall, the GRP system includes eight measures of research output, with each of the following two measures being repeated for the three time periods (2007-09, 2010-12, and 2013-15) and for the full period (2007-2015): volume (count of articles and reviews published) and visibility-adjusted volume (volume weighted by the average 5YIF of a respective journal).

We eliminated all non-educational organizations from the datasets. These included corporate entities, government agencies, and pure research centers. Business schools have a mission as educators to undertake research and disseminate it through education (Bessant et al., 2003). The core mission of research institutes is research alone, thus they have different resource allocation and talent configurations. We collected the addresses for all institutions to avoid duplication where they have been identified under different names by different authors. ${ }^{7}$

\footnotetext{
${ }^{6}$ The whole-count method creates double counting at a country level (e.g., if two schools from the USA are listed on a paper, this generates a USA count of two). The conceptual focus of the GRP system is on institutional output. This method is the best available to acknowledge the contribution of each school to overall research performance. As the method is applied to all organizations in the GRP system, it does not bias the relative standing of institutions.

${ }^{7}$ We put significant effort into compiling our data to make sure that an institution does not appear in the GRP system more than once; however, it is possible that some business schools may have multiple entries in the GRP under slightly different names. We welcome any feedback in relation to this issue, which we will use to produce GRP 2.0 covering research outputs in 2016-2018.
}

To provide additional insights into the field of IB research, we identified seven IB journals in our list of 149. Our selection heuristic was based on three sources: Harzing's JQL (59th edition), CABS (2015) list and the list of IB journals compiled by Tüselmann et al. (2016). We started by comparing the lists of IB journals provided in three sources and identifying the journals present in all of them. Then we compared the resulting list of 13 journals with the GRP list, selected on the basis of the average 5YIF (2007-2015). This applied the visibility-based filter to IB outlets, allowing us to focus on the most prominent IB journals. This narrowed the list down to five journals. In the final step we added two journals present in the list by Tüselmann et al. (2016) and in the GRP list, which gave us the final list of seven journals for the IB subset of the GRP. The following journals were included: Journal of World Business, Journal of International Business Studies, Global Strategy Journal, Journal of International Management, International Business Review, Asia Pacific Journal of Management, and Management and Organization Review. Publications in these journals were collected and processed in the same way as the main GRP system to form the IB subset of the GRP system. ${ }^{8}$

Our research information system seeks to complement bibliometric databases, such as Web of Science or Scopus. Our system uses a small fraction of the data contained in the Web of Science database (representing $5 \%$ of the entire population of journals in the Social Sciences Citation Index). To gain a deeper insight into institutions' research performance, one must use the Web of Science, where detailed information about authorship, scientific collaboration, funding, research themes, and journals, among other useful data, is available.

\subsection{Analysis of the data in the GRP system}

To improve the legitimacy of the IB field, its relative contribution must be demonstrated to the wider field of business and management research. Thus, we conducted a comparative descriptive analysis of GRP and its country-level distribution. To test the robustness of the IB elements of the GRP system, we compared the IB subset of the GRP system to the three most recent IB rankings (Lahiri \& Kumar, 2012; ; Xu et al., 2014).

We also thought it necessary to provide an empirical illustration for our conceptual reasoning on the importance of receivers' own performance, for the interpretation of research quality signals in the global signaling. To do this, we conducted cluster analysis in Stata 13 to identify the average levels of performance typical for the top, middle, and bottom clusters of institutions in each of the 127 countries in our dataset. As we knew the number of clusters that we wanted to see in advance, we used the $k$-means approach with the squared Euclidean distance measure, as recommended by Mingers and Harzing (2007). We repeated the same procedure for the IB subset of the GRP system.

\section{Results}

Journals in the GRP system published 389,785 institutional units of output (87,439 between 2007 and 2009, 132,317 between 2010 and 2012, and 170,030 between 2013 and 2015). ${ }^{9}$ Geographically, this output originates from 3352 institutions in 127 countries, with 53.1\% of these 389,785 produced in North America and 68\% produced by AACSB-accredited institutions. In the IB field, we identified that 1029 institutions in 75 countries published at least one paper in any of the seven IB journals in our system. Institutions located in English speaking countries dominate the ranks of top performers in the GRP system, with 79 institutions in the top 100 by total weighted output in $2007-2015$

\footnotetext{
${ }^{8}$ The GRP system includes three worksheets. The first worksheet, named "GRP Business \& Management". The second worksheet includes the IB subset of the GRP system. The third worksheet includes cluster analysis of both.

${ }^{9}$ Recall that output units are calculated by multiplying the number of articles published by the average 5-year impact factor (5YIF) of journals where these papers are published. So, for example, 1 unit is equal to 1 publication in a journal with a 5YIF of 1 .
} 


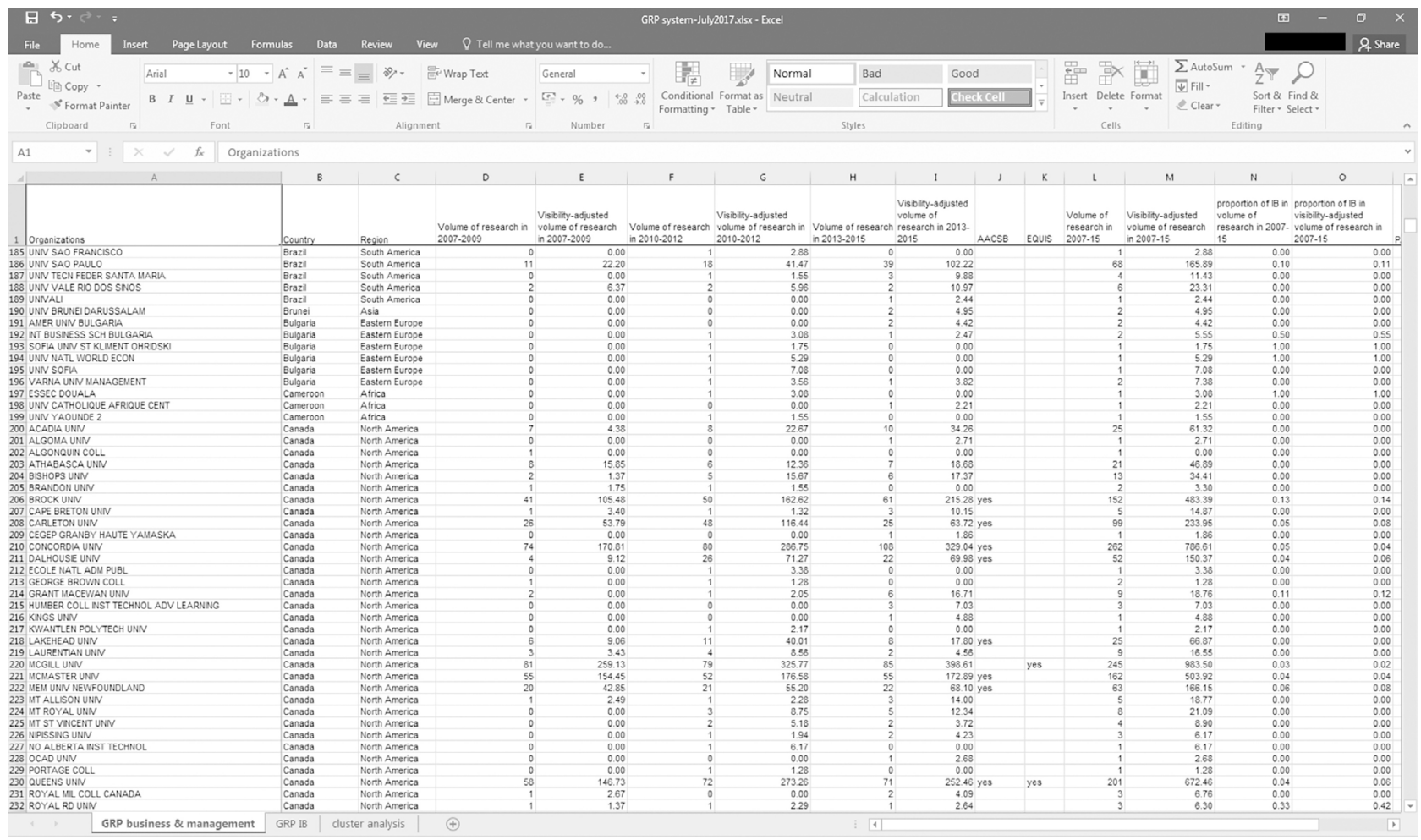

Fig. 1. General view of the Global Research Performance (GRP) system.

and 146 institutions in the top 200 by the same metric. The rest of top stratum is populated by institutions located in the countries where English is just one of several official languages (e.g., Singapore) or where English is not an official language (e.g., Netherlands). Examples of institutions that successfully bridged the language gap are Erasmus University in the Netherlands, INSEAD in France/Singapore, Copenhagen Business School in Denmark, and Hong Kong University of Science and Technology.

The general view of the GRP system is presented in Fig. 1. To facilitate the construction of national and regional comparisons, we included the country and geographical region of each organization in the system. Comparison groups do not have to be limited by institutions of similar research performance. Depending on the purpose of the comparison, reference groups can be made based on research performance (similar or aspirational), geography, size, accreditation (AACSB/ EQUIS), governance structure, and many other categories. The GRP system also includes information on the proportion of publications in IB journals in the overall output of an institution. GRP system users can sort the database by this proportion and see which institutions place an emphasis on IB. This new indicator becomes meaningful above a certain threshold of research performance, so we suggest a two-step procedure to define an institution's standing in the field of IB. First, a user should sort institutions by overall research performance output and identify institutions that have an acceptable level of performance as defined by the user's standards. Second, the user should sort the sub-set of institutions with acceptable research performance by the proportion of publications in IB journals to identify those that place emphasis on the IB discipline.

The comparison of the distribution of research output by country for the entire GRP system and for the IB subset shows that the field of IB is more decentralized than that of business and management research. The USA and Canada contribute $53 \%$ of business and management research, but only $36 \%$ of IB research. There is also a trend for the increasing internationalization of IB research. Chan, Fung, and Leung (2006) found that, in 1995-2004, 45\% of IB research was produced by the USA. Our analysis shows that in $2007-2015$ only $30 \%$ of IB research was produced by the USA. Longitudinal analysis of the IB subset of the GRP shows that the number of countries contributing research to IB journals has increased by $20 \%$, from 51 in 2007-09 to 61 in 2013-15. The same numbers for the entire GRP dataset are 89 countries in 2007-09 and 118 countries in 2013-15, which is equal to more than $32 \%$ growth.

In comparing the IB subset with three recent rankings of IB institutions, it is important to remember that direct pairwise comparison is difficult due to different metrics of research performance. Lahiri and Kumar (2012) used number of articles as their performance measure, Treviño et al. (2010) used the normalized count of published pages weighted by the IF of the journal, and Xu et al. (2014) the citation count. Recall that in our article we use the number of papers weighted by the 5YIF of the journal and our focus is on global visibility of institutions rather than their relative standing. We have compared the rankings by coverage of the IB field and consistency of institution representation. Lahiri and Kumar (2012) presented 25 institutions in eight countries, Treviño et al. (2010) 40 institutions in nine countries, and Xu et al. (2014) 50 institutions in ten countries. In contrast, the IB subset of the GRP includes 1029 institutions in 75 countries and subsumes institutions present in prior IB rankings.

To illustrate the importance of recognizing that different geographical markets may have different definitions of high and low performance, Table 3 presents the mean of visibility-adjusted research performance (cumulative for 2007-2015) for top, middle, and bottom clusters of institutions within each of the 27 countries which contributed at least $1 \%$ of global research output (the full table of cluster analysis results for all countries is included as a separate worksheet in the GRP system). In the same table, we also provide the number of institutions in each cluster. ${ }^{10}$ To get deeper insights from these results, consider selecting countries with similar number of institutions present in the GRP but located in the different geographical regions. For

\footnotetext{
${ }^{10}$ Due to the use of whole-count method, the absolute performance figures may be inflated for all countries, but the relative standing of performance does not change.
} 
Table 3

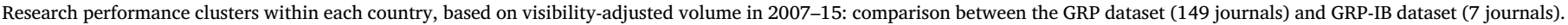

\begin{tabular}{|c|c|c|c|c|c|c|c|c|c|c|c|c|}
\hline \multirow[t]{2}{*}{ Country } & \multicolumn{2}{|c|}{ Top cluster } & \multicolumn{2}{|c|}{$\begin{array}{l}\text { Number of institutions in top } \\
\text { cluster }\end{array}$} & \multicolumn{2}{|c|}{ Middle cluster } & \multicolumn{2}{|c|}{$\begin{array}{l}\text { Number of institutions in middle } \\
\text { cluster }\end{array}$} & \multicolumn{2}{|c|}{ Bottom cluster } & \multicolumn{2}{|c|}{$\begin{array}{l}\text { Number of institutions in bottom } \\
\text { cluster }\end{array}$} \\
\hline & GRP & GRP-IB & GRP & GRP-IB & GRP & GRP-IB & GRP & GRP-IB & GRP & GRP-IB & GRP & GRP-IB \\
\hline Australia & 1331.98 & 89.250 & 4 & 4 & 563.59 & 34.158 & 7 & 8 & 105.43 & 6.174 & 29 & 15 \\
\hline Austria & 496.57 & 77.262 & 3 & 1 & 66.11 & 20.769 & 5 & 1 & 11.40 & 7.492 & 18 & 1 \\
\hline Belgium & 650.25 & 38.255 & 5 & 3 & 156.99 & 11.041 & 4 & 3 & 19.62 & 3.517 & 15 & 4 \\
\hline Canada & 1565.92 & 123.350 & 6 & 3 & 608.03 & 47.231 & 11 & 7 & 54.28 & 11.672 & 58 & 24 \\
\hline China & 573.11 & 70.685 & 7 & 7 & 218.55 & 23.900 & 12 & 11 & 12.55 & 3.270 & 197 & 53 \\
\hline Denmark & 1724.74 & 224.524 & 1 & 1 & 479.87 & 13.971 & 2 & 2 & 65.91 & 3.878 & 8 & 2 \\
\hline Finland & 873.09 & 97.525 & 2 & 2 & 182.30 & 29.713 & 9 & 3 & 11.46 & 7.191 & 22 & 3 \\
\hline France & 1494.53 & 62.318 & 2 & 3 & 204.42 & 16.524 & 24 & 5 & 18.48 & 4.164 & 98 & 20 \\
\hline Germany & 652.13 & 28.617 & 6 & 4 & 179.25 & 11.766 & 35 & 16 & 21.82 & 3.166 & 114 & 36 \\
\hline Hong Kong/PRC & 1569.64 & 180.021 & 5 & 2 & 429.99 & 65.973 & 2 & 4 & 14.07 & 6.861 & 10 & 7 \\
\hline India & 276.99 & 26.046 & 2 & 2 & 41.43 & 7.614 & 9 & 7 & 4.85 & 2.860 & 86 & 10 \\
\hline Ireland & 477.64 & 32.573 & 1 & 2 & 120.39 & 10.911 & 6 & 3 & 10.20 & 2.107 & 9 & 1 \\
\hline Israel & 419.64 & 26.376 & 6 & 2 & 109.47 & 9.897 & 1 & 3 & 14.79 & 3.385 & 22 & 8 \\
\hline Italy & 1711.27 & 54.441 & 1 & 1 & 297.03 & 15.480 & 6 & 4 & 43.80 & 3.754 & 75 & 25 \\
\hline Japan & 166.46 & 17.086 & 4 & 3 & 48.89 & 4.385 & 14 & 12 & 5.92 & 0.868 & 92 & 9 \\
\hline Netherlands & 3007.57 & 117.087 & 2 & 3 & 1013.69 & 31.037 & 7 & 5 & 61.44 & 5.242 & 28 & 8 \\
\hline New Zealand & 447.87 & 27.16 & 2 & 1 & 230.23 & 25.625 & 5 & 2 & 5.05 & 12.166 & 4 & 3 \\
\hline Norway & 595.42 & 36.269 & 2 & 2 & 151.49 & 12.268 & 6 & 1 & 14.82 & 2.349 & 28 & 4 \\
\hline Singapore & 2173.22 & 117.054 & 1 & 1 & 1178.42 & 63.829 & 2 & 1 & 17.16 & 29.118 & 4 & 1 \\
\hline South Korea & 720.04 & 74.631 & 3 & 2 & 238.39 & 16.337 & 7 & 7 & 15.57 & 3.790 & 114 & 22 \\
\hline Spain & 530.16 & 31.180 & 6 & 10 & 189.06 & 8.010 & 17 & 8 & 35.34 & 2.872 & 54 & 18 \\
\hline Sweden & 572 & 91.186 & 3 & 2 & 231.08 & 19.692 & 9 & 3 & 30.30 & 5.604 & 19 & 9 \\
\hline Switzerland & 831.69 & 32.559 & 3 & 2 & 331.90 & 8.379 & 6 & 2 & 22.12 & 2.938 & 32 & 8 \\
\hline Taiwan & 586.93 & 30.764 & 3 & 5 & 188.61 & 10.787 & 15 & 7 & 21.46 & 3.233 & 121 & 34 \\
\hline Turkey & 237.34 & 16.911 & 4 & 4 & 45.85 & 5.567 & 10 & 5 & 6.79 & 2.067 & 75 & 11 \\
\hline UK & 1359.49 & 90.563 & 11 & 7 & 487.44 & 33.860 & 28 & 24 & 61.39 & 6.844 & 99 & 45 \\
\hline USA & 2603.05 & 99.735 & 29 & 14 & 875.47 & 33.961 & 87 & 45 & 47.40 & 6.391 & 759 & 239 \\
\hline
\end{tabular}

example, Hong Kong and Ireland have 17 and 16 institutions respectively. For Ireland, the high-performance standard would be set around 478 units of visibility-adjusted output in a nine-year period. Approximately 120 units of visibility-adjusted output would be considered medium performance, and around 10 units would be low standard. In contrast, for Hong Kong, the high-performance standard is set at around 1570 units of visibility-adjusted research output; 430 units of visibilityadjusted output would be considered middle-level, and 14 units of output is a mean standard of the bottom cluster.

Similar cluster analysis for the IB subset of the GRP, presented in the same table, reveals global "IB powerhouses" - countries, where IB performance in the top cluster is higher than 100 units of visibilityadjusted output. There are five such IB powerhouses is our dataset, namely, Denmark, Hong Kong, Canada, the Netherlands, and Singapore, with performance in top cluster equal to 225, 180, 123, 117 and 117 units, respectively. This cluster analysis shows countries where highly productive IB institutions are located (although these are not necessarily the countries with the highest overall volume of IB research).

\section{Discussion and directions for future research}

Our paper makes several contributions with implications for IB theory and practice and, more broadly, to business and management. We describe these next.

\subsection{The internationalization of business schools}

Research on the internationalization of knowledge-intensive service-industry firms highlights the importance of talent mobility in developing firm-level IB capabilities (Brock, 2012). Yet, when the legitimacy of new entrants to international markets is discussed, the focus is on the reputational signals sent to potential customers (Bello, Radulovich, Javalgi, Scherer, \& Taylor, 2016; Guillotin \& Mangematin, 2015; Zhang et al., 2015). Our paper emphasizes the equal importance of legitimacy signaling in global labor markets, where knowledge-intensive service-industry firms seek to attract new organizational members with necessary international capabilities.

The GRP system has significant practical value for the hiring and retention of international faculty in non-globally prominent business schools. International hiring is an iterative process. Organizations send signals to the labor market and applicants respond by signaling their quality (Bangerter, Roulin, \& König, 2012). Job market signaling research indicates that job applicants are attracted to organizations that have a positive reputation and that align with their professional social identity (Bangerter et al., 2012; Chapman et al., 2005). The quality of the research environment plays several important roles here. First, it proves that an institution is committed to producing research, increasing social identity fit with potential applicants (Day, 2011). Second, by demonstrating support for research, an institution ensures that employees joining it have an opportunity to grow their research portfolio and stay employable (Callie \& Cheslock, 2008; Richardson \& McKenna, 2003). Third, standing in research-based rankings becomes a powerful driver of prestige, supported by the rhetoric that describes top institutions as "world-class," "leading," and "elite" (Enders, 2014; Wedlin, 2011). By creating legitimacy signals, research attracts applicants who seek to identify themselves with prominent organizations (Highhouse, Thornbury, \& Little, 2007). Fourth, providing ex ante information on the quality of the research environment improves the retention of talent (Richardson, McBey, \& McKenna, 2008). In the absence of a global signaling system, applicants pay more attention to employers they are familiar with because of prominent global status (Celani \& Singh, 2011) or personal connections.

When a global signaling system is not available to support hiring decisions, non-globally prominent institutions often rely on cognitive shortcuts, such as familiarity bias, to identify potential candidates. This often leads to prioritizing candidates from globally prominent schools (Sang et al., 2017) or those who are referred by personal networks. In identifying academics from globally prominent institutions as potential new employees (and doctoral students), business schools expect these 
academics to increase the global legitimacy of an institution by creating globally visible outputs themselves and by transferring their knowledge to other employees, to help them produce similarly valued outputs (Slavova, Fosfuri, \& De Castro, 2015).

In many cases, however, these expectations do not materialize. First, even if business schools that currently produce relatively low amounts of research can attract academics from globally prominent schools, they are not always successful in retaining talent. SIEs generally have limited allegiance to their host organization (Doherty, 2013). For academics from globally prominent schools, moving to such organizations may be associated with a change in culture and difficult workplace integration. Second, the portability of researchers' performance across different organizations may be imperfect (Aguinis \& O’Boyle, 2014; Groysberg et al., 2008). When mobility takes researchers far from their network of co-authors (in terms of geography, status, or governance mechanisms), there may be detrimental effects on their research productivity. Third, knowledge transfer to new colleagues may not be a priority for new hires. Seeking to deliver the research promise on which they have been hired, researchers hired from globally prominent schools may prefer working with their established external network rather than building an internal one in the new institution.

Given these challenges, we suggest that international hiring would benefit from extending its focus to include higher number of international applicants from institutions with similar research performance. Business schools are increasingly using rankings as rhetorical devices to promote themselves as "elite" institutions (Wedlin, 2011). The GRP system offers an opportunity to replace decision-making based on halo effects of this rhetoric by data-driven decision-making. Users of the GRP system can decide which threshold of research performance is more congruent with their definition of "research elite." For instance, the nine-year performance threshold for the top 100 institutions is equal to 990 units of visibility-adjusted output (i.e. papers weighted by the average 5YIF), the threshold for the top 200 institutions is equal to 508 units, and the threshold for the top 1000 institutions is equal to 40 units of output.

Future research on international hiring of SIEs by non-globally prominent institutions can benefit from integrating the insights from the GRP system with the typology of organizational forms developed at the university level by Whitley (2012). This typology categorizes universities based on the extent to which they can act as strategic actors. Business schools' category in this typology might be a driver of international hiring, assuming that schools with more autonomy have better opportunities in relation to talent acquisition. Higher strategic autonomy can also be an impediment to the attraction of SIEs, if business schools' strategic behavior led to Darwinian processes in local markets, with a small number of institutions dominating the market.

\subsection{The efficiency of global signaling: theoretical implications}

Global mobility of academic SIEs depends on the ability of employers and applicants to signal their quality in global labor markets. This brings forward two interconnected conceptual questions. First, who determines the general threshold level of performance in global markets, so that the performance above this level is interpreted as the signal of high quality, and the performance below this threshold level is interpreted as the signal of low quality? Second, is there a consensus among all signal receivers in a global signaling system in relation to this threshold level of performance?

The generally adopted signaling model (e.g., by Besancenot, Faria, \& Vranceanu, 2009) is based on an implicit assumption that each receiver of the signal has a market-wide awareness of different levels of signals and their influence on performance. In the global market environment, it is unlikely that a business school can achieve this awareness. Studies in cognitive strategy provide strong empirical evidence that even within local markets organizations tend to pay attention to a subset of similar organizations rather than the entire industry
(McNamara, Luce, \& Tompson, 2002; Porac, Thomas, \& Baden-Fuller, 1989).

Therefore, in answering the first question, we can conclude that organizations are dependent on information provided by a third party which has a bird's-eye view of the market and can define the threshold of high performance. The empirical evidence of the extent to which business schools have become dependent on global rankings in their decision making (e.g., Adler \& Harzing, 2009; Hommel \& Thomas, 2014; Wedlin, 2011) supports this conclusion. By placing research on global rankings (e.g., Enders, 2014) within the context of signaling theory, we can apply theoretical principles to the assessment of the quality of rankings, rather than just observe general trends in the development of these rankings and forces that shape them.

In answering the second question, the data in the GRP system strongly indicate that, in a diverse global business school industry, a "one size fits all" definition for high level of research performance does not exist. While the highest absolute levels of research performance are accepted as a high-quality signal by all receivers, moderate levels of research performance may be interpreted as high-quality, low-quality, or acceptable-quality signals depending on the receiver. A simple sorting of the GRP shows that research performance conforms to a heavy-tailed distribution, which is consistent with previous research (Aguinis, O’Boyle, Gonzalez-Mulé, \& Joo, 2016; Joo, Aguinis, \& Bradley, 2017). While a small number of organizations produce a high volume of research, the majority of institutions perceive moderate (relative to those in top schools) volumes of research as acceptable or even desirable level of performance. We should accept that, even when we have the benefit of a global insight into the levels of research performance, complex international markets require us to step away from simplified binary heuristics and adopt a more pluralistic approach that accommodates multiple points of view.

The principle of pluralism also applies to the measurement of research performance (Aguinis, Shapiro, Antonacopoulou, \& Cummings, 2014). There is no single opinion on the single best metric to measure research performance, with most sources recommending the use of multiple metrics as best practice (e.g., Aguinis, Shapiro, Antonacopoulou, \& Cummings, 2014; Hicks et al., 2015). Comparison of the IB subset of our dataset with some of the existing rankings of IB institutions reveals the importance of the choices made in relation to performance indicators. Each of the metrics used by us and in previous work measures a different aspect of research performance, which may align with different strategic objectives on the part of business schools sending and receiving research performance signals. For example, the strategy of publishing fewer papers in highly visible journals can be balanced with that of publishing more papers in lower-ranking outlets (Seibert, Kacmar, Kraimer, Downes, \& Noble, 2017). ${ }^{11}$ Therefore, when we refer to signaling through research performance, we are actually referring to a bundle of interconnected signals, which might have different degree of importance to the receiver. Identifying the types of quality signals to which different groups of organizations respond in the global business school industry may become an interesting avenue for future research at the intersection of signaling theory, IB research and scientometrics.

\subsection{Additional practical implications for the field of $I B$}

For the gatekeepers of the field of IB, the ability to observe the dynamics of publications in IB journals across three time periods in the GRP system gives an opportunity to identify the "emerging" IB institutions within the subset of schools with relatively low performance.

\footnotetext{
${ }^{11}$ This strategy could be counterbalanced by field-level mechanisms, where either the influx of submissions to a lower-ranked journal leads to its higher selectivity due to the competition for limited space in that journal, or local research evaluation committees become extra vigilant in relation to publications in perceived "easy option" journals.
} 
For example, Middlesex University (UK) has increased the visibilityadjusted output in IB journals from 1.87 units in 2007-09 to 5.18 units in 2010-12, and 22.41 units in 2013-2015. To maintain their momentum, such institutions might need support from the IB community in the form of collaboration, location of the IB conferences, and other forms of knowledge sharing.

Language offers an interesting lens for future research on the development of the field of IB. The data in the GRP show that scholars outside the USA produce two thirds of all publications in prominent IB journals. The countries that drive this IB research performance are predominantly English speaking, but have smaller domestic markets than the US and are often in close interaction with their non-English speaking neighbors. This helps them accumulate interesting IB insights and publish them in English language journals. Further exploration of geographical distribution of IB research can consider "linguascapes" within business schools (Steyaert, Ostendorp, \& Gaibrois, 2011). Such exploration can have both conceptual value for IB research on the role of language (e.g., Itani et al., 2015; Neeley, 2013; Tenzer \& Pudelko, 2017) and practical value for supporting IB scholars in non-English speaking countries.

\subsection{Concluding comments}

In summary, GRP offers several contributions for IB research and practice. First, by using signaling theory as a conceptual framework, it enables us to leverage insights from the literature on international academic careers and from scientometric research into research on the internationalization of business schools. Second, for IB researchers in non-globally prominent institutions, it provides a signaling tool that can communicate the impact of their research in local, regional, and global contexts. This can increase the IB research visibility of their schools, which can form a part of a suite of strategies that IB research teams use to attract high-quality resources, such as students, researchers, corporate partners or funders, to their institution. Third, for IB researchers considering career mobility, using GRP allows for the identification of the broadest ever range of institutions supporting IB research as potential workplaces.

Our study also offers additional contributions that are related to IB, albeit less directly, because they are broader in nature. For a broad audience of academic managers (i.e., university administrators including deans, department chairs, and other decision makers) developing internationalization strategies for their institutions, the GRP provides theory-driven insights into the rules of global competition, offering a middle ground between individual academics' (often dismissive) view of the rankings, and organizations' need to have a signaling system that makes sense of the industry. From a managerial perspective, rankings are a fact of life. Managers need measurement systems that are clear, transparent, reproducible, and also need to predict cause-effect relations between actions that they can take and outcomes in the ranking. The main elements of our GRP system remain within the control of an institution. Specifically, investing more in strategic initiatives (e.g., compensation systems) and resources (e.g., hiring more research active faculty) that should lead to more publications in the 149 journals which, in turn, will translate into improved research performance. This is of considerable value to university managers in making decisions about investment in research and its direct impact on improved global visibility. Our study also facilitates resourcing decisions for hiring committees by delivering data-driven insights into SIEs' organizational backgrounds. Finally, we challenge the established rhetoric that puts English speaking countries, in particular the USA and the UK, in the center of global research prominence. If performance trends in our data persist, in the near future these countries will have to share the limelight with China and Germany, whose output is growing in double digits while the USA output is stagnating.

\section{Acknowledgements}

We thank Jonathan Doh and three Journal of World Business anonymous reviewers for highly constructive and detailed feedback that allowed us to improve our manuscript substantially.

An earlier version of this manuscript is one of five finalists for the 2016 Academy of Management (AOM) Carolyn Dexter Award given to the paper that best meets the objective of internationalizing AOM. We thank the reviewers of the AOM Management Education \& Development division for their feedback on an earlier version of this paper.

\section{Appendix A. Supplementary data}

Supplementary data associated with this article can be found, in the online version, at http://dx.doi.org/10.1016/j.jwb.2017.09.003.

\section{References}

Adler, N. J., \& Harzing, A. W. (2009). When knowledge wins: Transcending the sense and nonsense of academic rankings. Academy of Management Learning \& Education, 8, 72-95.

Aguinis, H., \& O'Boyle, E. (2014). Star performers in twenty-first-century organizations. Personnel Psychology, 67, 313-350.

Aguinis, H., Shapiro, D. L., Antonacopoulou, E. P., \& Cummings, T. G. (2014). Scholarly impact: A pluralist conceptualization. Academy of Management Learning \& Education, $13,623-639$.

Aguinis, H., O’Boyle, E., Gonzalez-Mulé, E., \& Joo, H. (2016). Cumulative advantage: Conductors and insulators of heavy-tailed productivity distributions and productivity stars. Personnel Psychology, 69, 3-66.

Aguinis, H., Cascio, W. F., \& Ramani, R. S. (2017). Science's reproducibility and replicability crisis: International business is not immune. Journal of International Business Studies, 48, 653-663.

Baden-Fuller, C., \& Ang, S. H. (2001). Building reputations: The role of alliances in the European business school scene. Long Range Planning, 34, 741-755.

Bangerter, A., Roulin, N., \& König, C. J. (2012). Personnel selection as a signaling game. Journal of Applied Psychology, 97, 719-738.

Bello, D. C., Radulovich, L. P., Javalgi, R. R. G., Scherer, R. F., \& Taylor, J. (2016). Performance of professional service firms from emerging markets: Role of innovative services and firm capabilities. Journal of World Business, 51, 413-424.

Besancenot, D., Faria, J. R., \& Vranceanu, R. (2009). Why business schools do so much research: A signaling explanation. Research Policy, 38, 1093-1101.

Bessant, J., Birley, S., Cooper, C., Dawson, S., Gennard, J., Gardiner, M., et al. (2003). The state of the field in UK management research: Reflections of the Research Assessment Exercise (RAE) Panel. British Journal of Management, 14, 51-68.

Brock, D. M. (2012). Building global capabilities: A study of globalizing professional service firms. The Service Industries Journal, 32, 1593-1607.

Caligiuri, P., \& Bonache, J. (2016). Evolving and enduring challenges in global mobility. Journal of World Business, 51, 127-141.

Callie, T. M., \& Cheslock, J. J. (2008). Hiring and compensation practices of business school deans. The Review of Higher Education, 32, 25-49.

Celani, A., \& Singh, P. (2011). Signaling theory and applicant attraction outcomes. Personnel Review, 40, 222-238.

Chan, K. C., Fung, H. G., \& Leung, W. K. (2006). International business research: Trends and school rankings. International Business Review, 15, 317-338.

Chapman, D. S., Uggerslev, K. L., Carroll, S. A., Piasentin, K. A., \& Jones, D. A. (2005). Applicant attraction to organizations and job choice: A meta-analytic review of the correlates of recruiting outcomes. Journal of Applied Psychology, 90, 928-944.

Connelly, B. L., Certo, S. T., Ireland, R. D., \& Reutzel, C. R. (2011). Signaling theory: A review and assessment. Journal of Management, 37, 39-67.

Cuervo-Cazurra, A., Andersson, U., Brannen, M. Y., Nielsen, B., \& Reuber, A. R. (2016). Can I trust your findings? Ruling out alternative explanations in international business research. Journal of International Business Studies, 47, 881-997.

Day, N. E. (2011). The silent majority: Manuscript rejection and its impact on scholars. Academy of Management Learning \& Education, 10, 704-718.

Doherty, N. (2013). Understanding the self-initiated expatriate: A review and directions for future research. International Journal of Management Reviews, 15, 447-469.

Enders, J. (2014). The academic arms race: International rankings and global competition for world-class universities. In A. M. Pettigrew, E. Cornuel, \& U. Hommel (Eds.). The institutional development of business schools (pp. 155-175). Oxford University Press.

Erkkilä, T. (2013). Global university rankings: Challenges for European higher education. Springer.

Floyd, S. W., Schroeder, D. M., \& Finn, D. M. (1994). Only if I'm first author: Conflict over credit in management scholarship. Academy of Management Journal, 37, 734-747.

Groysberg, B., Lee, L. E., \& Nanda, A. (2008). Can they take it with them? The portability of star knowledge workers' performance. Management Science, 54, 1213-1230.

Guillotin, B., \& Mangematin, V. (2015). Internationalization strategies of business schools: How flat is the world? Thunderbird International Business Review, 57, 343-357.

Harvey, M. G., \& Moeller, M. (2016). A brief commentary on the past: Present and future trajectory of the Journal of World Business. Journal of World Business, 51, 6-9. 
Harzing, A. W., \& Adler, N. J. (2016). Disseminating knowledge: From potential to reality-new open-access journals collide with convention. Academy of Management Learning \& Education, 15, 140-156.

Harzing, A. W. (2016). Journal quality list (57th ed.). [Available from http://www.harzing.com/resources/journal-quality-list. Accessed 05/12/16].

Hertig, H. P. (2016). Universities, rankings and the dynamics of global higher education: Perspectives from Asia, Europe and North America. Springer.

Hicks, D., Wouters, P., Waltman, L., de Rijcke, S., \& Rafols, I. (2015). The Leiden Manifesto for research metrics. Nature, 520, 429-431.

Highhouse, S., Thornbury, E. E., \& Little, I. S. (2007). Social-identity functions of attraction to organizations. Organizational Behavior and Human Decision Processes, 103, 134-146.

Hommel, U., \& Thomas, H. (2014). Research on business schools: Themes, conjectures, and future directions. In A. M. Pettigrew, E. Cornuel, \& U. Hommel (Eds.). The institutional development of business schools (pp. 6-38). Oxford: Oxford University Press.

Horta, H. (2009). Global and national prominent universities: Internationalization, competitiveness and the role of the State. Higher Education, 58, 387-405.

Itani, S., Järlström, M., \& Piekkari, R. (2015). The meaning of language skills for career mobility in the new career landscape. Journal of World Business, 50, 368-378.

Joo, H., Aguinis, H., \& Bradley, K. J. (2017). Not all non-normal distributions are created equal: Improved theoretical and measurement precision. Journal of Applied Psychology, 102, 1022-1053.

Kacmar, K. M., \& Whitfield, J. M. (2000). An additional rating method for journal articles in the field of management. Organizational Research Methods, 3, 392-406.

Kumar, V., \& Kundu, S. K. (2004). Ranking the international business schools: Faculty publication as the measure. Management International Review, 44, 213-228.

Lahiri, S., \& Kumar, V. (2012). Ranking international business institutions and faculty members using research publication as the measure. Management International Review, $52,317-340$.

Linton, J. D. (2012). Business school research and rankings: Where do the schools really stand? Technovation, 32, 1-5.

Mangematin, V., \& Baden-Fuller, C. (2008). Global contests in the production of business knowledge: Regional centres and individual business schools. Long Range Planning, 41, 117-139.

McNamara, G. M., Luce, R. A., \& Tompson, G. H. (2002). Examining the effect of complexity in strategic group knowledge structures on firm performance. Strategic Management Journal, 23, 153-170.

Mingers, J., \& Harzing, A. W. (2007). Ranking journals in business and management: A statistical analysis of the Harzing data set. European Journal of Information Systems, 16, 303-316.

Mingers, J., \& Yang, L. (2017). Evaluating journal quality: A review of journal citation indicators and ranking in business and management. European Journal of Operational Research, 257, 323-337.

Neeley, T. B. (2013). Language matters: Status loss and achieved status distinctions in global organizations. Organization Science, 24, 476-497.

Pendlebury, D. A. (2008). Using bibliometrics in evaluating research. Thomson Reuters White Paper. Retrieved 29 August, 2015, from http://wokinfo.com/media/mtrp/ UsingBibliometricsinEval_WP.pdf.

Pherali, T. J. (2012). Academic mobility, language, and cultural capital: The experience of transnational academics in British higher education institutions. Journal of Studies in International Education, 16, 313-333.

Pidd, M., \& Broadbent, J. (2015). Business and Management Studies in the 2014 Research Excellence Framework. British Journal of Management, 26, 569-581.

Podsakoff, P. M., MacKenzie, S. B., Podsakoff, N. P., \& Bachrach, D. G. (2008). Scholarly influence in the field of management: A bibliometric analysis of the determinants of university and author impact in the management literature in the past quarter century. Journal of Management, 34, 641-720.

Polonsky, M., \& Ringer, A. C. (2009). The global and regional dispersion of publishing in the field of international marketing. Journal of Global Marketing, 22, 155-172.

Porac, J. F., Thomas, H., \& Baden-Fuller, C. (1989). Competitive groups as cognitive communities: The case of Scottish knitwear manufacturers. Journal of Management
Studies, 26, 397-416.

Richardson, J., \& McKenna, S. (2003). International experience and academic careers: What do academics have to say? Personnel Review, 32, 774-795.

Richardson, J., McBey, K., \& McKenna, S. (2008). Integrating realistic job previews and realistic living conditions previews. Realistic recruitment for internationally mobile workers. Personnel Review, 37, 490-508.

Sang, K., Lockett, N., Mendelsohn, F., Nibbs, A., \& Brueggemann, B. J. (2017). Access all areas. Times Higher Education, 18(May), 35-41.

Saunders, J., Wong, V., \& Saunders, C. (2011). The research evaluation and globalization of business research. British Journal of Management, 22, 401-419.

Seibert, S. E., Kacmar, K. M., Kraimer, M. L., Downes, P. E., \& Noble, D. (2017). The role of research strategies and professional networks in management scholars' productivity. Journal of Management, 43, 1103-1130.

Serenko, A., \& Bontis, N. (2011). What's familiar is excellent: The impact of exposure effect on perceived journal quality. Journal of Informetrics, 5, 219-223.

Slavova, K., Fosfuri, A., \& De Castro, J. O. (2015). Learning by hiring: The effects of scientists' inbound mobility on research performance in academia. Organization Science, 27, 72-89.

Spence, M. (1973). Job market signaling. The Quarterly Journal of Economics, 87, 355-374.

Stern, N. (2016). Building on success and learning from experience: An independent review of the Research Excellence Framework. London: Department for Business, Energy and Industrial Strategy.

Steyaert, C., Ostendorp, A., \& Gaibrois, C. (2011). Multilingual organizations as 'linguascapes': Negotiating the position of English through discursive practices. Journal of World Business, 46, 270-278.

Tüselmann, H., Sinkovics, R. R., \& Pishchulov, G. (2015). Towards a consolidation of worldwide journal rankings-a classification using random forests and aggregate rating via data envelopment analysis. Omega, 51, 11-23.

Tüselmann, H., Sinkovics, R. R., \& Pishchulov, G. (2016). Revisiting the standing of international business journals in the competitive landscape. Journal of World Business, $51,487-498$.

Tenzer, H., \& Pudelko, M. (2017). The influence of language differences on power dynamics in multinational teams. Journal of World Business, 52, 45-61.

Thomas, H., Lorange, P., \& Sheth, J. (2013). The business school in the twenty-first century. Cambridge: University Press.

Treviño, L. J., Mixon, F. G., Funk, C. A., \& Inkpen, A. C. (2010). A perspective on the state of the field: International business publications in the elite journals as a measure of institutional and faculty productivity. International Business Review, 19, 378-387.

Usher, A., \& Medow, J. (2009). A global survey of university rankings and league tables. In B. M. Kehm, \& B. Stensaker (Vol. Eds.), University rankings, diversity, and the new landscape of higher education: Vol. 18, (pp. 3-18). Sense Publishers.

Wedlin, L. (2011). Going global: Rankings as rhetorical devices to construct an international field of management education. Management Learning, 42(2), 199-218 p.1350507610389683.

Whitley, R. (2012). Transforming universities: National conditions of their varied organisational actorhood. Minerva, 50, 493-510.

Willmott, H. (2011). Journal list fetishism and the perversion of scholarship: Reactivity and the ABS list. Organization, 18, 429-442.

Wilsdon, J., Allen, L., Belfiore, E., Campbell, P., Curry, S., Hill, S., et al. (2015). The metric tide: Report of the independent review of the role of metrics in research assessment and managementhttp://dx.doi.org/10.13140/RG.2.1.4929.1363. Available online at http://blogs.lse.ac.uk/impactofsocialsciences/files/2015/07/2015_metrictide.pdf.

Xu, S., Yalcinkaya, G., \& Seggie, S. H. (2008). Prolific authors and institutions in leading international business journals. Asia Pacific Journal of Management, 25, 189-207.

Xu, N., Poon, W. P., \& Chan, K. C. (2014). Contributing institutions and authors in international business research: A quality-based assessment. Management International Review, 54, 735-755.

Zhang, X., Zhong, W., \& Makino, S. (2015). Customer involvement and service firm internationalization performance: An integrative framework. Journal of International Business Studies, 46, 355-380. 